\title{
Biodegradation of Natural Estrogens by Biofilms from Biological Activated Carbon: Effect of Temperature
}

\author{
Xuan Guo ${ }^{1 *}$, Fusheng Li $^{2}$, Denny Helard ${ }^{1}$, Toshiyuki Kawaguchi ${ }^{2}$ \\ ${ }^{1}$ Graduate School of Engineering, Gifu University, Gifu, Japan \\ ${ }^{2}$ River Basin Research Center, Gifu University, Gifu, Japan \\ Email: *p3812102@edu.gifu-u.ac.jp
}

Received August 16, 2012; revised September 13, 2012; accepted October 5, 2012

\begin{abstract}
In order to obtain information on the biodegradation potential of biofilms involved in the removal of natural estrogens by biological activated carbon (BAC) columns, batch degradation of estrone (E1) and $17 \beta$-estradiol (E2) at temperature of $5^{\circ} \mathrm{C}, 20^{\circ} \mathrm{C}$ and $35^{\circ} \mathrm{C}$ by biofilms from four BAC columns (packed with activated carbon of particle size ranging from $0.5-0.59 \mathrm{~mm}$ and $1.0-1.19 \mathrm{~mm}$ into two bed depths) was studied. The results indicated that $\mathrm{E} 2$ was degraded faster by than E1 at all three temperatures and with the increasing of temperature, the amount of E1 converted from E2 increased. By fitting observed concentration data with a first-order rate expression, the bio-mass based degradation rate constants $\left(k_{\mathrm{VSS}}\right)$ for $\mathrm{E} 1$ and $\mathrm{E} 2$ under all experimental conditions were estimated and linear relationship between $\ln k_{\mathrm{VSs}}$ and $1 / \mathrm{T}$ ( $\mathrm{T}$ $=$ absolute temperature) was demonstrated, resulting that with the increasing of the experimental temperature, degradation rate of biofilms for both E1 and E2 increased, and the increasing rate for E2 was higher than that for E1.
\end{abstract}

Keywords: Estrogens; Biofilms; Temperature; Biodegradation; BAC Columns

\section{Introduction}

Some chemicals that may disrupt the endocrine systems in humans and animals have received considerable attention in the scientific and public community. Such chemicals are widely referred as endocrine disrupting chemicals (EDCs). Natural estrogen $17 \beta$-estradiol (E2) and its main metabolite estrone (E1) are among the most potent EDCs [1]. In humans and mammalians, estrogens undergo various transformations mainly in the liver. Frequently, they are oxidized, hydroxylated, deoxidated and methylated prior to the final conjugation with glucuronic acid or sulphate. For instance, E2 is rapidly oxidized to E1 which can be further converted to estriol, the major excretion product in urine and faeces. They are excreted into wastewater by humans and mammals at $\mathrm{ng} / \mathrm{L}$ level [2], but even this amount is often high enough to cause endocrine disrupting effects in some aquatic species such as trouts [3]. Many studies have shown that exposure to EDCs during early development induces abnormalities in peripheral reproductive organs and in reproductive behaviors.

It has been generally observed that the sewage treatment plant (STP) with activated sludge can significantly reduce concentrations of estrogens [4], but leave fluctuating concentrations of estrogens in effluents. The dis-

*Corresponding author. charge of such effluents may be the main source for the wide distribution and occurrence of EDCs in surface water, groundwater, and even drinking water [5]. Even if certain percentages of discharged estrogens into natural water resource may get dissipated due to various physicochemical and biological reactions occurring therein [6] [7], the remaining percentages of them can enter drinking water treatment plants.

Activated carbon adsorption is highly expected for the removal of estrogens from drinking water sources. The removal efficiencies of estrogens by the granular activated carbon (GAC) have been tested in laboratory-scale batch reactors, continuous flow filters and full-scale filtration plants [8-10]. The effects of some fundamental environmental parameters including adsorbent concentration, $\mathrm{pH}$, salinity and the presence of humic acid and surfactant on adsorption were studied [5]. For example, Fukuhara and co-workers showed that GAC adsorption capacity for E2 in the pure water was about thousands times higher than that for E2 in the river water [9]. They attributed the reduction in GAC adsorption capacity for E2 to site competition and pore blockage that occurred on the GAC surface due to the presence of constituents in the river water. Adsorption performance of estrogens on the biological activated carbon (BAC), which was made by coating GAC with biofilms, was also investigated. In a previous study [11], it was found that E2 was readily 
removed via a combination of adsorption and biodegradation by BAC columns. Biodegradation of E2 by the BAC columns was confirmed because of the detection of $\mathrm{E} 1$, which is the biotransformation byproduct of E2. In another recent study [12], removal of E2 from the drinking water in BAC reactors was obtained, showing that BAC had superior performance to GAC in removing estrogens due to the additional microbial degradation.

As mentioned above, adsorption and biodegradation are known to be the predominant processes contributing to estrogens removal during the BAC filtration. However, it is difficult to identify the relative significance of the two processes, and the development of mathematical models to simulate the removal efficiency of BAC columns requires understanding of the individual contribution.

Unfortunately, information on the biodegradation behavior of estrogens by biofilms from activated carbon adsorbers was insufficient. These biofilms were coated on the surface of GAC to generate BAC or gradually formed on the surface of GAC without intentional seeding. A previous study [11] has shown that the removal values of E2 in BAC columns were, by several percentage points, lower than those in GAC columns. They presumed that the blockage of the pore openings by biological films composing of microbes and that some of their viscous metabolic macromolecular products may inhibit E2 access into pores where the adsorption takes place. However, the reason behind was still not clear. Thus, in order to know the biodegradation potential involved in the removal of estrogens by BAC columns, quantitative evaluation is necessary. In addition, it has been indicated that seasonal changes affected removal efficiency of estrogens in the sewage treatment plant [3], as biological growth may increase with ambient temperature [13]. For example, a previous study [14] on aerobic batch degradation of E2 by activated sludge has shown that temperature is a factor greatly affecting the removal of E2 by biodegradation, as larger removals were observed at higher temperatures. Therefore, it is inferable that biodegradation of estrogens by biofilms is affected by temperature. However, little was known about the temperature dependence of estrogens removals by biofilms from BAC columns biodegradation removal of E1 and E2 by biofilms from BAC columns, and the temperature effect involved.

As the first study which examines the biodegradation behavior of estrogens by biofilms from BAC columns under different temperatures, the main objectives were to investigate the temperature effect on the biodegradation of E1 and E2 and provide biodegradation rate constant which need for modeling simulation of the estrogens removal efficiency by BAC columns.

\section{Materials and Methods}

\subsection{Biological Activated Carbon Columns}

Biofilms used in this study were obtained from four BAC columns, which were packed with different particle sizes of activated carbon to two different bed depths. Fixed bed conditions for BAC columns are shown in Table 1. Filtrasorb 400 (Calgon Co., USA), a well-used granular activated carbon, was chosen as the adsorbent. BAC columns were generated by coating four packed GAC columns with microorganisms detached from the riverbed sediment of Nagara River. The coating of the microorganisms for four BAC columns was achieved by circulating $500 \mathrm{~mL}$ of the detached riverbed suspension (the suspended solid concentration was $5100 \mathrm{mg} / \mathrm{L}$ ) to each column at a flow rate of $9.0 \mathrm{~mL} / \mathrm{min}$ for 48 hours.

Adsorption experiments were conducted by using these BAC columns since November, 2005. After being filtered through $0.45 \mu \mathrm{m}$ membrane filters (Tokyo Roshi, Japan), Nagara River water was supplied in the influent reservoir to all columns in a down-flow mode with pumps at a constant flow rate of $2.5 \mathrm{~mL} / \mathrm{min}$. All columns were operated at constant temperature of $20^{\circ} \mathrm{C}$. During experiments, E2 was intermittently spiked into the influent for several times in order to investigate the behavior of E2 in BAC columns where adsorbable NOM molecules contained in the river water were continuously adsorbed. After running for five and half years, the removals for NOM with the index of UV260 (UV-absorbance at $260 \mathrm{~nm}$ ) were $-14 \%,-31 \%, 27 \%$ and $4 \%$ by BAC-1, BAC-2, BAC-3 and BAC-4, respectively, and no $\mathrm{E} 2$ was detected from the effluents of all BAC columns.

Table 1. Fixed bed conditions for BAC columns.

\begin{tabular}{ccccc}
\hline Column & Activated carbon size $(\mathrm{mm})$ & Bed depth $(\mathrm{cm})$ & Apparent bed porosity (\%) & Empty bed contact time (min) \\
\hline BAC-1 & $0.5-0.59$ & 10 & 32.1 & 19.5 \\
BAC-2 & $0.5-0.59$ & 20 & 32.1 & 39.0 \\
BAC-3 & $1.0-1.19$ & 10 & 13.0 & 19.5 \\
BAC-4 & $1.0-1.19$ & 20 & 13.0 & 39.0 \\
\hline
\end{tabular}




\subsection{Biofilms Preparation}

Biofilms were obtained by carefully backwashing each column with $3 \mathrm{~L}$ Milli-Q water. After one-day settlement (at $20^{\circ} \mathrm{C}$ ), the overlying water was pumped out. Then the settled substance in Milli-Q water was centrifuged at $3500 \mathrm{rpm}$ for $10 \mathrm{~min}$ for further decreasing the water contained. The concentrated biofilms were sampled and subjected to observation by scanning electron microscope (SEM), no activated carbon particle was observed. Obtained biofilms were separate evenly to sterilized reactors for experiments.

\subsection{Stock Solution of Natural Estrogens}

Pre-weighed amounts of E1 and E2 powders (Wako pure chemical Co., Osaka Japan) were separately added to glass bottles filled with $0.5 \mathrm{~L}$ of Milli-Q water to make initial suspension concentrations at about $0.04 \mathrm{~g} / \mathrm{L}$ for each analyte. Organic solvent was not used in order to eliminate its effect on degradation of natural estrogens. After stirring for about 24 hours, the solutions were filtered using pre-washed $0.2 \mu \mathrm{m}$ PTFE membrane filters, and the filtrate obtained was then used as the stock solutions of both compounds and refrigerated stored in dark at $5^{\circ} \mathrm{C}$ prior to use. The concentration of E1 and E2 in each stock solution was about 600 and $1000 \mu \mathrm{g} / \mathrm{L}$, respectively.

\subsection{Batch Experiment Method}

Two series of batch experiments were performed using biofilms from BAC columns based on the conditions shown in Table 2. The first series were designed for investigating the degradation behaviors of $\mathrm{E} 2$ at different temperatures by biofilms from BAC-1, BAC-2, BAC-3 and BAC-4. In the second series, biofilms from BAC-2 and BAC-4 were selected to study the degradation behaviors of E1 under various temperatures. For each run, biofilms from the four columns were analyzed by measuring the suspended solids (SS), the volatile suspended solids (VSS) (Table 2) and the densities of general and heterotrophic bacteria. Organic content in the biofilms was described in the form of VSS/SS, VSS/SS values for biofilms from BAC-1, BAC-2, BAC-3 and BAC-4 fall into range of $0.77-0.79,0.74-0.81,0.82-0.84$ and 0.79 -0.91 , respectively.

The densities of general and heterotrophic bacteria of the biofilms were determined by quantifying the bacteria number concentration in the suspension of the biofilms following the conventional plate culture method. For the culture method, after dilutions, $1 \mathrm{~mL}$ of each suspension was placed to a sterile plate and then poured with $10 \mathrm{~mL}$ of melted standard culture agar which consisted of weighted amount of peptone, yeast extract, glucose, agar powder and Milli-Q water.

Batch experiments were performed using sterilized $500 \mathrm{~mL}$-flasks which were placed on water-bath shakers with adjustable water temperature. For each reactor, after being filtered through $0.2 \mu \mathrm{m}$ PTFE membrane filters, $300 \mathrm{~mL}$ of Nagara River water was added with the collected biofilms. River water was filtered in order to exclude the possibility of effect from the bacteria exist there on the biodegradation behaviors of E1 and E2. Water quality of the used Nagara River water was investi-

Table 2. Batch experimental conditions.

\begin{tabular}{|c|c|c|c|c|c|c|}
\hline Series & Run No & Column & Temperature $\left({ }^{\circ} \mathrm{C}\right)$ & Initial concentration $(\mu \mathrm{g} / \mathrm{L})$ & $\mathrm{SS}(\mathrm{g} / \mathrm{L})$ & $\operatorname{VSS}(g / L)$ \\
\hline \multirow{8}{*}{ E2 } & 1 & BAC-2 & 5 & 30 & 0.011 & 0.008 \\
\hline & 2 & BAC-4 & 5 & 30 & 0.022 & 0.020 \\
\hline & 3 & BAC-1 & 20 & 30 & 0.083 & 0.066 \\
\hline & 4 & BAC-2 & 20 & 30 & 0.029 & 0.023 \\
\hline & 5 & BAC-3 & 20 & 30 & 0.054 & 0.044 \\
\hline & 6 & BAC-4 & 20 & 30 & 0.033 & 0.030 \\
\hline & 7 & BAC-1 & 35 & 30 & 0.019 & 0.015 \\
\hline & 8 & BAC-3 & 35 & 30 & 0.008 & 0.007 \\
\hline \multirow{6}{*}{ E1 } & 9 & & 5 & 30 & 0.040 & 0.030 \\
\hline & 10 & BAC-2 & 20 & 30 & 0.038 & 0.029 \\
\hline & 11 & & 35 & 30 & 0.024 & 0.018 \\
\hline & 12 & & 5 & 30 & 0.014 & 0.012 \\
\hline & 13 & BAC-4 & 20 & 30 & 0.028 & 0.022 \\
\hline & 14 & & 35 & 30 & 0.024 & 0.021 \\
\hline
\end{tabular}


gated under the conditions: $\mathrm{pH}$ of 7.6, dissolved organic carbon (DOC) of $0.95 \mathrm{mg} / \mathrm{L}$, UV260 of $1.09 / \mathrm{m}$, electricity conductivity (EC) of $8.75 \mathrm{mS} / \mathrm{m}$ and dissolved oxygen (DO) of $5.37 \mathrm{mg} / \mathrm{L}$. Bath water temperatures were adjusted in advance to desired levels at $5^{\circ} \mathrm{C}, 20^{\circ} \mathrm{C}, 35^{\circ} \mathrm{C}$, respectively. After the filtered river water was added to reactors with biofilms and reached desired temperatures ( $\sim 5$ min was needed), the stock solution of E1 or E2 was spiked to obtain initial concentration of $30 \mu \mathrm{g} / \mathrm{L}$. The reactors were shaken in the dark throughout the experimental period $200 \mathrm{~h}$ ) to eliminate the possibility of photo degradation of estrogens inside. Intermittent monitoring of $\mathrm{pH}$ and $\mathrm{DO}$ in the reactors showed a small fluctuation at $\mathrm{pH} 7.6$ and $6.2 \mathrm{mg} / \mathrm{L} \mathrm{DO}$. The sampling time intervals were designed as $t=0.08,0.17,0.5,1,2,4,8,11,24,35$, $48,72,96,120,140$ and $196 \mathrm{~h}$ after spiking of E1 or E2. For each sampling, about $10 \mathrm{~mL}$ of the mixed suspension of biofilms and river water was taken into a $15 \mathrm{ml}$ centrifuge tube after being filtered through $0.45 \mu \mathrm{m}$ membrane filters and then subjected to analysis.

E1 and E2 were analyzed using an Agilent 1100 series liquid chromatography/mass spectrometry (LC/MS) system (HP1100MSD; CA, USA). The setting conditions of which are shown in Table 3. For every commencing of the analysis, calibration was performed using 10 and 50 $\mu \mathrm{g} / \mathrm{L}$ of both E1 and E2 standard solutions with a methanol content of $20 \%$ in $\mathrm{v} / \mathrm{v}$. To minimize measurement errors, two internal standards, namely $17 \beta$-estradiol-C4 and estrone-C4 (Hayashi Pure Chemical Ind., Co., Ltd.), were added to all samples, and the identification and quantification were made in negative SIM mode by following the well-used internal standard methodology [3, 15]. The target ions for E1 and E2 were 269 and 271, respectively. By adopting a large injection volume (i.e., 25 $\mu \mathrm{L}$ ), the detection limits reached a level of about 0.01 $\mu \mathrm{g} / \mathrm{L}$ for both targeted species.

Significant differences in the means of parameters between different treatments were tested based on oneway analysis of variance (ANOVA) with mean separation by Tukey's significant difference (HSD) test at 95\% confidence level using the software of STATISTIC 8.0.

\section{Results and Discussion}

\subsection{Degradation Behaviors of E1 and E2}

The concentration profiles of E1 and E2 spiked separately into respective reactors under various temperatures are illustrated in Figures $\mathbf{1}$ and 2. For all runs, the lower the temperature, the higher the residual concentration, thus indicating a significant impact of liquor temperature on the biodegradation of E1 and E2 from the aqueous phase over the studied rang of $5^{\circ} \mathrm{C}-35^{\circ} \mathrm{C}$, in agreement with those observed by Li et al. (2005) [14]. For instance, for runs where E1 was spiked into reactors with biofilms from BAC-4 (Figure 1), the spiked E1 $(30 \mu \mathrm{g} / \mathrm{L})$ decreas-
Table 3. Major LC/MS parameters used for detection of E1 and E2.

\begin{tabular}{ccc}
\hline Instrument & & HP1100MSD \\
\hline \multirow{2}{*}{ LC } & Column & Zorbax Eclipes \\
& & XDB-C8 \\
& & $(4.6 \Phi \times 150 \mathrm{~mm})$ \\
& & A: Acetonitrile $/$ Methanol $=60: 40$ \\
& Flow-rate & B: Methanol 5000 \\
& Column temperature & $0.4 \mathrm{~mL} \cdot \mathrm{min}^{-1}$ \\
& Injection volume & $40^{\circ} \mathrm{C}$ \\
& Ion source & $25 \mu \mathrm{L}$ \\
\hline MS & Mode & ESI \\
& Capillary voltage & Negative $(\mathrm{SIM})$ \\
& Fragmentor & $3000 \mathrm{~V}$ \\
& Nebulizer pressure & $70 \mathrm{~V}$ \\
& Drying gas flow $\left(\mathrm{N}_{2}\right)$ & $35 \mathrm{psi}$ \\
& Drying gas temperature & $12 \mathrm{~L} \cdot \mathrm{min}^{-1}$ \\
\hline
\end{tabular}

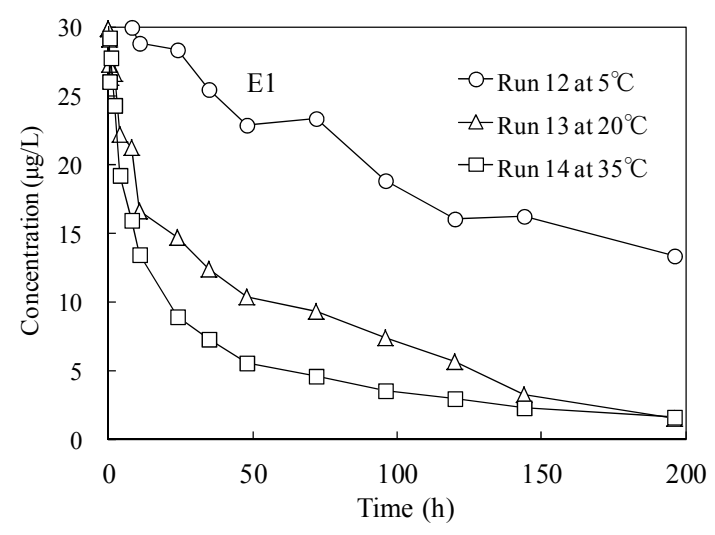

Figure 1. Concentration profiles of E1 observed when E1 was spiked.

ed to $22.9,10.3$ and $5.6 \mu \mathrm{g} / \mathrm{L}$ after $48 \mathrm{~h}$ at $5^{\circ} \mathrm{C}, 20^{\circ} \mathrm{C}$ and $35^{\circ} \mathrm{C}$, respectively, with the residual concentration at $5^{\circ} \mathrm{C}$ being about 4 times higher than that at $35^{\circ} \mathrm{C}$. A reduction in the removal by about $41.6 \%$ (from $65.3 \%$ to $23.7 \%$ ) was obtained as the temperature decreased from 20 to $5^{\circ} \mathrm{C}$; and a further reduction by about $57.6 \%$ (from $81.3 \%$ to $23.7 \%$ ) was obtained as the temperature was lowered from 35 to $5^{\circ} \mathrm{C}$. After $196 \mathrm{~h}$-operation, the spiked $\mathrm{E} 1$ decreased to 1.64 and $1.54 \mu \mathrm{g} / \mathrm{L}$ from the aqueous phase at $20^{\circ} \mathrm{C}$ and $35^{\circ} \mathrm{C}$, respectively. At $5^{\circ} \mathrm{C}$, however, its residual concentration was $13.38 \mu \mathrm{g} / \mathrm{L}$ corresponding to a removal of $55.4 \%$.

For runs where E2 was spiked into reactors with biofilms from BAC-2 under $5^{\circ} \mathrm{C}$ and $20^{\circ} \mathrm{C}$ (Figure 2(a)), similar temperature-dependent removals of estrogens 


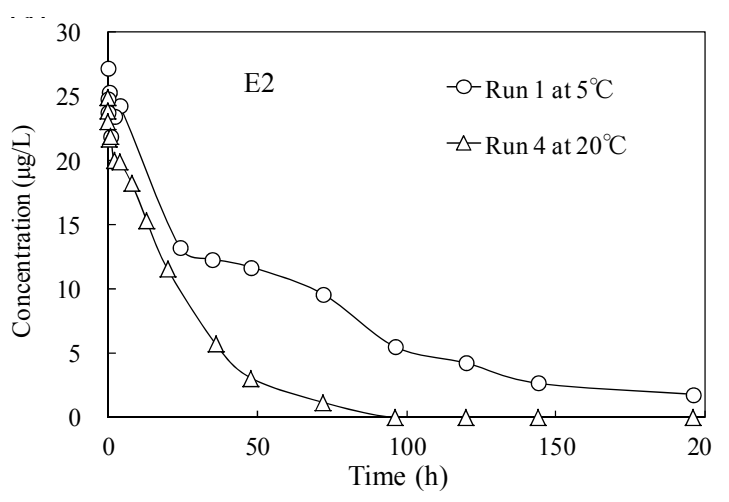

(a)

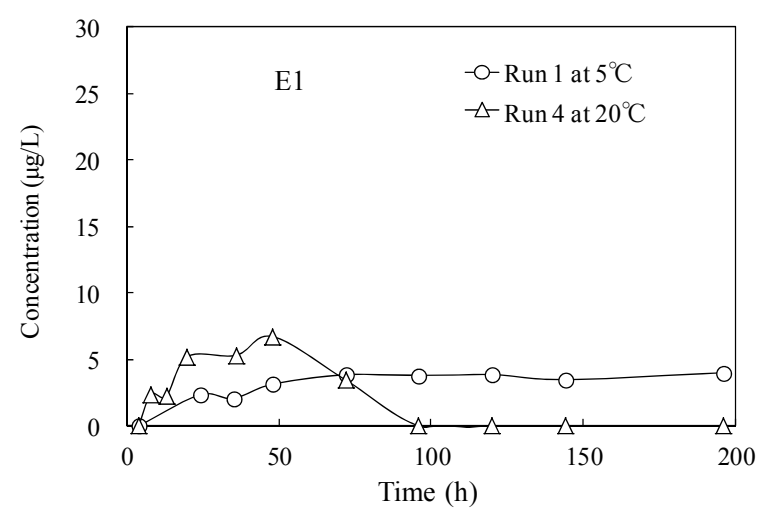

(b)

Figure 2. Concentration profiles of (a) E2 observed when E2 was spiked, (b) E1 emerged when E2 was spiked.

were observed (comparisons of concentration profiles obtained under $20^{\circ} \mathrm{C}$ and $35^{\circ} \mathrm{C}$ were not shown). Nevertheless, the spiked E2 $(30 \mu \mathrm{g} / \mathrm{L})$ decreased to 11.37 and $3.08 \mu \mathrm{g} / \mathrm{L}$ after $48 \mathrm{~h}$ at $5^{\circ} \mathrm{C}$ and $20^{\circ} \mathrm{C}$, respectively. The value was less than $50 \%$ of the residual concentration of $\mathrm{E} 1$ at the same sampling time, indicating that biofilms can degrade E2 faster than E1 under the same temperature conditions. It should be noted that E1 and E2 adsorbed on the biofilms were insignificant. This consideration is reasonable if referring to a recent study [4], in which the removal of E2 and $17 \alpha$-ethinylestradiol (EE2) in continuous flow biofilm reactors were mainly ascribed to the microbial degradation, as no E2 or EE2 were detected in the solid biofilms.

D'Ascenzo et al. (2003) [15] pointed out that E1 was probably the most important natural endocrine disrupting compound present in most natural water environments. This is probably true because that: 1) the quantities of E1 discharged from STPs into receiving water body are more than 10 times larger than those of E2; 2) E1 possesses an estrogenic potency weaker than E2 but much stronger than nonylphenol and its precursors; and 3) some conjugated species of E1 may get disassociated after reaching receiving water bodies. Therefore, when the behavior of E2 degradation was investigated, the ap- parent conversion from E2 to E1 under all experiment conditions was also examined. For all runs, E1 was detected during the biodegradation of the spiked E2. From the results of Run 1 and 4 (Figure 2(b)), E1 was firstly detected at sampling time of 24 and $8 \mathrm{~h}$ corresponding to a concentration of 2.32 and $2.38 \mu \mathrm{g} / \mathrm{L}$, respectively. After running for about another 96 and $40 \mathrm{~h}$, it was clear that E1 reached its maximum level of 3.89 and $6.70 \mu \mathrm{g} / \mathrm{L}$, respectively. Based on the maximum concentrations of $\mathrm{E} 1\left(C_{\mathrm{E} 1 \max }\right)$ and spiked concentrations of $\mathrm{E} 2\left(C_{\mathrm{E} 20}\right)$, the apparent conversion ratios from E2 to E1 were simply calculated using the ratios of $C_{\mathrm{E} 1 \max }$ to $C_{\mathrm{E} 20}$. The specific value for Run 1 and 4 was $12.9 \%, 22.3 \%$, respectively. By increasing the experiment temperature, the conversion ratio increased, thus suggesting that the high temperature was responsible for more amount of E1 converted from E2. Similar trends of the increased E1 conversion ratio with the increasing temperature were observed from the results of other runs (data were not shown).

\subsection{Degradation Rate Constants of E1 and E2}

To further compare the degradation behavior of E1 and E2 at varied temperatures, the degradation rate constants of E1 and E2 spiked into relative reactors were derived by assuming a first-order reaction as described below

$$
\mathrm{d} C / \mathrm{d} t=-k \mathrm{C}
$$

where $C$ is the concentration $(\mu \mathrm{g} / \mathrm{L}), t$ is the time (h) and $k$ is the apparent first-order degradation rate constant $(/ \mathrm{h})$. $k$ was approximated by fitting the experimental plots, $\ln \left(C / C_{0}\right)$ versus $t$, with the following rewritten linear format

$$
\ln \left(C / C_{0}\right)=-k t
$$

$C_{0}$ is the initial concentration of targeted compound involved directly in the assumed first-order rate reactions. To prove the assumption that the decrease in concentrations of E1 and E2 in the presence of biofilms followed the first-order rate reaction, the concentrations calculated based on the first-order rate constants (from Run 3 and Run 8) were plotted against time in Figure 3. Clear visible was that the calculated and observed data fitted well with high correlation coefficient (from $\mathrm{R}^{2}=0.588$ 0.994), as shown in Table 4. Based on the estimated $k$ value (data was not shown) and corresponding VSS levels, the biomass-based average degradation rate constants $k_{\mathrm{VSS}}$ from all experiment runs, which were described in the form of rate per $\mathrm{g} / \mathrm{L}$ of VSS, were further determined as shown in Table 4. A trend of increase in the $k_{\mathrm{Vss}}$ with increasing temperature was revealed for both E1 and E2. For example, when only E1 spiked into reactor with biofilms from column BAC-4, the $k_{\mathrm{VSS}}$ value increased from 0.431 to $0.877\left(\mathrm{~h}^{-1} / \mathrm{g} / \mathrm{L}\right)$ when temperature was 
changed from $5^{\circ} \mathrm{C}$ to $35^{\circ} \mathrm{C}$. As compared to the $k_{\mathrm{VSS}}$ values of $\mathrm{E} 1$, which was ranged from 0.430 to $1.196\left(\mathrm{~h}^{-1} / \mathrm{g} / \mathrm{L}\right)$ over the temperature of $5^{\circ} \mathrm{C}-35^{\circ} \mathrm{C}$ observed from Run 9 - 14, the $k_{\mathrm{V} s \mathrm{v}}$ value of E2 was in the range of 0.437 to $3.900\left(\mathrm{~h}^{-1} / \mathrm{g} / \mathrm{L}\right)$ obtained from Run 1-6. These comparison results provided evidence that degradation of E2 exhibited a higher rate than the degradation of E1.Similar results were reported in a study [3] concerning the behavior and occurrence of estrogens in municipal STP. Average $k_{\mathrm{VSS}}$ values of runs operated at the same temperature were calculated and the differences between degradation rates of E1 and E2 by biofilms at different temperatures were revealed in Figure 4. It was clear that under all temperature conditions the average $k_{\mathrm{VSS}}$ value of E2 was higher than that of E1. For both E1 and E2, no significant difference was obtained for average $k_{\mathrm{VSS}}$ value between $5^{\circ} \mathrm{C}$ and $20^{\circ} \mathrm{C}$ or $20^{\circ} \mathrm{C}$ and $35^{\circ} \mathrm{C}(p>0.05)$. However, significant different of those value between $5^{\circ} \mathrm{C}$ and $35^{\circ} \mathrm{C}$ was obtained (E1: $p<0.02$, E2: $p<0.03$ ).

Figure 5 shows the microbial density of biofilms from BAC columns. It can be seen that for both general and heterotrophic bacteria, the bacteria number of biofilms obtained from BAC-3 and BAC-4 (packed with activated carbon having particle size ranging from $1.0-1.19 \mathrm{~mm}$ ) were higher than those from BAC-1 and BAC-2 (packed with activated carbon having particle size ranging from

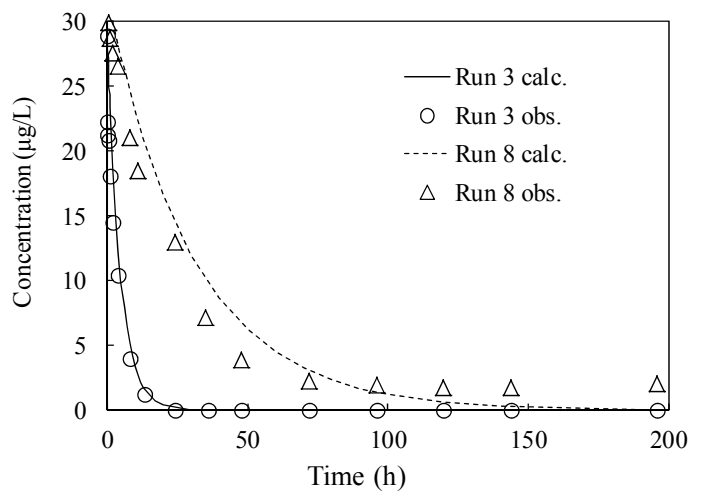

Figure 3. Description of batch degradation of $\mathrm{E} 2$ by the first-order reaction.
$0.5-0.59 \mathrm{~mm})$. It is probably because of the different activated carbon surface area between BAC-3 and BAC- 1 or BAC-4 and BAC-2, surface area of large-size activated carbons in BAC-3 and BAC-4 was smaller than that of small-size ones in BAC-1 and BAC-2, biofilms formed on the surface of larger-size activated carbon was thicker than that formed on the surface of small-size ones, and more living bacteria could colonize in the thicker biofilms. On the contrary, the difference in the bacteria number among the biofilms from BAC columns with different bed depths was not significantly observed. Note that the higher microbial density did not correlate with higher biomass-based degradation rate constants $k_{\mathrm{vss}}$ (Table 5), suggesting that the number of estrogen-de-

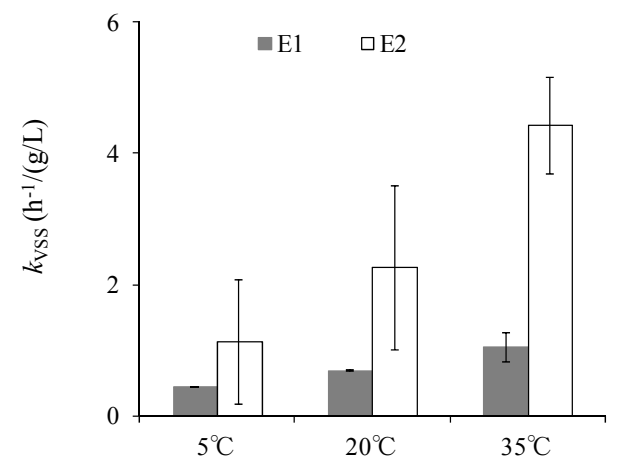

Figure 4. Comparison of average biomass-based degradation rate constants from runs at same temperatures.

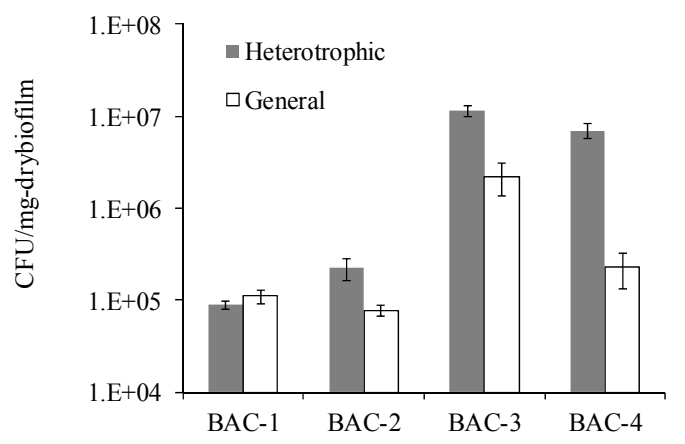

Figure 5. Microbial density of biofilms from BAC columns.

Table 4. The biomass-based degradation rate constants estimated for all experimental runs at different temperatures.

\begin{tabular}{|c|c|c|c|c|c|c|c|}
\hline & & \multicolumn{2}{|c|}{$5^{\circ} \mathrm{C}$} & \multicolumn{2}{|c|}{$20^{\circ} \mathrm{C}$} & \multicolumn{2}{|c|}{$35^{\circ} \mathrm{C}$} \\
\hline & & $k_{\mathrm{VSS}}\left(\mathrm{h}^{-1} / \mathrm{g} / \mathrm{L}\right)$ & $\mathrm{R}^{2}$ & $k_{\mathrm{VSS}}\left(\mathrm{h}^{-1} / \mathrm{g} / \mathrm{L}\right)$ & $\mathrm{R}^{2}$ & $k_{\mathrm{VSS}}\left(\mathrm{h}^{-1} / \mathrm{g} / \mathrm{L}\right)$ & $\mathrm{R}^{2}$ \\
\hline \multirow{4}{*}{ E2 } & BAC-1 & & & 3.651 & 0.961 & 3.900 & 0.906 \\
\hline & BAC-2 & 1.812 & 0.970 & 1.826 & 0.994 & & \\
\hline & BAC-3 & & & 0.744 & 0.840 & 4.943 & 0.955 \\
\hline & BAC-4 & 0.437 & 0.951 & 2.792 & 0.990 & & \\
\hline \multirow{2}{*}{ E1 } & BAC-2 & 0.430 & 0.894 & 0.678 & 0.588 & 1.196 & 0.647 \\
\hline & BAC-4 & 0.431 & 0.951 & 0.694 & 0.942 & 0.877 & 0.687 \\
\hline
\end{tabular}


Table 5. Comparison of degradation rate constants of this study with previous studies.

\begin{tabular}{|c|c|c|c|c|c|c|}
\hline & Initial concentration $(\mu \mathrm{g} / \mathrm{L})$ & Matrix & Temperature $\left({ }^{\circ} \mathrm{C}\right)$ & $k_{\mathrm{SS}}\left(\mathrm{h}^{-1} / \mathrm{g} / \mathrm{L}\right)$ & $k_{\mathrm{VSS}}\left(\mathrm{h}^{-1} / \mathrm{g} / \mathrm{L}\right)$ & References \\
\hline \multirow{10}{*}{ E2 } & $10-50$ & Activated sludge & 5 & 0.851 & 0.796 & Li et al. [14] \\
\hline & 30 & Biofilms & 5 & 1.034 & 1.125 & This study \\
\hline & $10-50$ & Activated sludge & 20 & 1.309 & 1.780 & Li et al. [14] \\
\hline & 30 & Activated sludge & 20 & 4.272 & 4.940 & Li et al. [16] \\
\hline & 1000 & Aquifer material & 20 & 0.003 & - & Ying et al. [17] \\
\hline & 15 & Sediment & 20 & 0.042 & - & Desmiarti et al. [18] \\
\hline & 30 & Biofilms & 20 & 1.963 & 2.253 & This study \\
\hline & 200 & Nitrifying activated sludge & 30 & 0.347 & - & Shi et al. [19] \\
\hline & $10-50$ & Activated sludge & 35 & 1.924 & 3.330 & Li et al. [14] \\
\hline & 30 & Biofilms & 35 & 3.581 & 4.421 & This study \\
\hline \multirow{7}{*}{ E1 } & 44.4 & Nitrifying activated sludge & 4 & 0.049 & - & Ren et al. [20] \\
\hline & 30 & Biofilms & 5 & 0.273 & 0.430 & This study \\
\hline & 30 & Activated sludge & 20 & 0.833 & 0.932 & Li et al. [16] \\
\hline & 100 & Activated sludge & 20 & 0.095 & - & Taro et al. [21] \\
\hline & 30 & Biofilms & 20 & 0.532 & 0.686 & This study \\
\hline & 200 & Nitrifying activated sludge & 30 & 0.010 & - & Shi et al. [19] \\
\hline & 30 & Biofilms & 35 & 0.820 & 1.036 & This study \\
\hline
\end{tabular}

-: data not available.

grading bacteria was not proportional to those of general and heterotrophic bacteria existing in biofilms.

In addition to the biomass-based degradation rate constants $k_{\mathrm{Vss}}$, the SS-based degradation rate constants $\left(k_{\mathrm{SS}}\right)$ were also calculated and comparisons of the $k_{\mathrm{SS}}$ and $k_{\mathrm{VSS}}$ values of E1 and E2 obtained in study with literature values are summarized in Table 5. The SS-based degradation rate constant of $\mathrm{E} 2$ obtained at $35^{\circ} \mathrm{C}$ increased by 10.3 times as compared to that obtained at $30^{\circ} \mathrm{C}$ in the literature [19]. Moreover, The degradation rate constant of E1 $\left(k_{\mathrm{SS}}\right)\left(0.273\right.$ and $\left.0.820 \mathrm{~h}^{-1} / \mathrm{g} / \mathrm{L}\right)$ at temperature 5 and $35^{\circ} \mathrm{C}$ was 5.6 and 82 times higher than that estimated for a nitrified activated sludge at temperature of $4^{\circ} \mathrm{C}$ and $30^{\circ} \mathrm{C}[19,20]$, respectively, suggesting that both $\mathrm{E} 1$ and E2 can be degraded faster by biofilms from BAC columns than by nitrified activated sludge used in their studies. It was further noticed that the $k_{\mathrm{SS}}$ value resulted from the degradation by biofilms was 1.2 - 5.6 times larger than that associated with the activated sludge at temperature of $5^{\circ} \mathrm{C}, 20^{\circ} \mathrm{C}$ and $35^{\circ} \mathrm{C}$. However, Li et al. (2008) [16] reported higher $k_{\mathrm{SS}}$ values, which might because more active bacteria available in the activated sludge used in that study for the degradation of E1 and E2.

\subsection{Temperature Effect on the Biomass-Based Degradation Rate Constants of E1 and E2}

Under all temperature conditions, the degradation rate of
E2 by biofilms was higher than that of E1. Similar result was observed from a study [19] using nitrifying activated sludge, showing that the degradation of estrogens followed the first-order reaction kinetics with the degradation rate constant of $0.056 \mathrm{~h}^{-1}$ for E1 and $1.3 \mathrm{~h}^{-1}$ for E2. To further compare the temperature effect on the biomass-based degradation rate constants of E1 and E2, a well-used expression was used. The relationship between the absolute experimental temperature $\mathrm{T}$ and the average $k_{\mathrm{VSS}}$ value was established by the following equation:

$$
\mathrm{dln} k_{\mathrm{vss}} / \mathrm{dt}=\mathrm{E}_{a} / \mathrm{RT}^{2}
$$

where $\mathrm{E}_{a}$ was activation energy and $\mathrm{R}$ was the gas constant. Linear relationship between $\ln k_{\mathrm{Vss}}$ and $1 / \mathrm{T}$ was demonstrated in Figure $6\left(R^{2}=0.986\right.$ for E2 and $R^{2}=$ 0.994 for E1). It was obvious that with the increase in $1 / T, \ln k_{\mathrm{Vss}}$ decreased, likely due to the increased biological growth with the increasing temperature. The decreasing rate of $\ln k_{\mathrm{VSS}}$ for $\mathrm{E} 2$ was higher than that for E1, as evidenced from a more negative slope (-4230.4) obtained for E2 compared to -2709.5 for E1. The observed larger $k_{\mathrm{VSS}}$ values of E1 and E2 at higher temperatures were in support of the earlier justification that sorption of estrogens by biofilms do not have an impact on their removal. Otherwise, a contrary trend should be revealed since physical sorption is an exothermic process. This result was consistent with that presented in the previous 


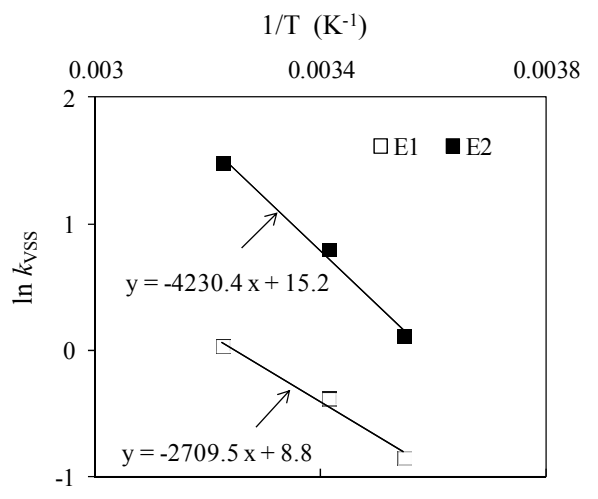

Figure 6. Effect of temperature on the biomass-based degradation rate constants.

study [14] which showed that the removal of E2 in the aerobic sludge process was faster at higher temperature, with the role of sorption by biomass being less signifycant.

\section{Conclusion}

Biodegradation of natural estrogens E1 and E2 by biofilms from different biological activated carbon columns were investigated by conducting batch degradation experiments under various temperature conditions. The results showed that biofilms can degrade both E1 and E2 under all experimental temperatures and performed better on the degradation of E2. The degradation rate constants for both E1 and E2 increased with the increase in the experimental temperature and the temperature effect was more pronounced for E2 degradation than for E1 degradation.

\section{REFERENCES}

[1] Z. Sebastian, D. Uwe and H. Thomas, "Determination of Estrogenic Steroids in Surface Water and Wastewater by Liquid Chromatography-Electrospray Tandem Mass Spectrometry," Journal of Separation Science, Vol. 28, No. 1, 2005, pp. 52-58. doi:10.1002/jssc. 200301727

[2] A. C. Johnson and J. P. Sumpter, "Removal of Endocrine Disrupting Chemicals in Activated Sludge Treatment Works," Environmental Science \& Technology, Vol. 35, No. 24, 2001, pp. 4697-4703. doi:10.1021/es010171j

[3] T. A. Ternes, P. Kreckel and J. Mueller, "Behavior and Occurrence of Estrogens in Municipal Sewage Treatment Plant-II: Aerobic Batch Experiment with Activated Sludge," Science of the Total Environment, Vol. 225, No. 1-2, 1999, pp. 91-99. doi:10.1016/S0048-9697(98)00335-0

[4] P. Christina and R. Wolfgang, "Investigation on the Removal of Natural and Synthetic Estrogens Using Biofilms in Continuous Flow Biofilm Reactors and Batch Experiments Analysed by Gas Chromatography/Mass Spectrometry," Water Research, Vol. 45, No. 3, 2011, pp. 11051114. doi:10.1016/j.watres.2010.10.034

[5] Z. H. Liu, K. Yoshinori and M. Satoshi, "Removal Me- chanisms for Endocrine Disrupting Compounds (EDCs) in Wastewater Treatment-Physical Means, Biodegradation, and Chemical Advanced Oxidation: A Review," Science of the Total Environment, Vol. 407, No. 2, 2009, pp. 731-748. doi:10.1016/j.scitotenv.2008.08.039

[6] K. M. Lai, K. L. Johnson, M. D. Scrimshaw and J. N. Lester, "Binding of Waterborne Steroid Estrogens to Solid Phase in River and Estuarine Systems," Environmental Science \& Technology, Vol. 34, No. 18, 2000, pp. 38903894. doi:10.1021/es9912729

[7] K. I. E. Holthaus, A. C. Johnson, M. D. Jurgens, R. J. Williams, J. J. L. Smith and J. E. Carter, "The Potential for Estradiol and Ethinylestradiol to Sorb to Suspended and Bed Sediments in Some English Rivers," Environmental Toxicology and Chemistry, Vol. 21, No. 12, 2002, pp. 2526-2532. doi:10.1002/etc.5620211202

[8] M. J. Benotti, R. A. Trenholm, B. J. Vanderford, J. C. Holady, B. D. Stanford and S. A. Snyder, "Pharmaceuticals and Endocrine Disrupting Compounds in US Drinking Water," Environmental Science \& Technology, Vol. 43, No. 3, 2009, pp. 597-603. doi:10.1021/es801845a

[9] T. Fukuhara, S. Iwasaki, M. Kawashima, O. Shinohara and I. Abe, "Adsorbability of Estrone and 17 Beta-Estrodiol in Water onto Activated Carbon," Water Research, Vol. 40, No. 2, 2006, pp. 241-248. doi:10.1016/j.watres.2005.10.042

[10] Y. P. Zhang and J. L. Zhou, "Removal of Estrone and 17 Beta Estradiol from Water by Adsorption," Water Research, Vol. 39, No. 16, 2005, pp. 3991-4003. doi:10.1016/j.watres.2005.07.019

[11] F. S. Li, A. Yuasa, H. Tanaka and Y. Katamine, “Adsorption and Biotransformation of $17 \beta$-Estradiol in Biological Activated Carbon Adsorbers," Adsorption, Vol. 14, No. 2-3, 2008, pp. 389-398. doi:10.1007/s10450-008-9105-1

[12] Z. T. Li, B. Dvorak and X. Li, "Removing $17 \beta$-Estradiol from Drinking Water in a Biologically Activated Carbon (BAC) Reactor Modified from a Granular Activated Carbon (GAC) Reactor," Water Research, Vol. 46, No. 9, 2012, pp. 2828-2836. doi:10.1016/j.watres.2012.03.033

[13] M. P. Fernandez, I. D. Buchanan and M. G. Ikonomou, "Seasonal Variability of the Reduction in Estrogenic Activity at a Municipal WWTP," Water Research, Vol. 42, No. 12, 2008, pp. 3075-3081. doi:10.1016/j.watres.2008.02.022

[14] F. S. Li, A. Yuasa, A. Obara and P. M. Alexander, "Aerobic Batch Degradation of $17 \beta$-Estradiol (E2) by Activated Sludge: Effects of Spiking E2 Concentrations, $\mathrm{M}_{\mathrm{LVSS}}$ and Temperatures," Water Research, Vol. 39, No. 10, 2005, pp. 2065-2075. doi:10.1016/j.watres.2005.02.009

[15] G. D’Ascenzo, A. D. Corcia, A. Gentili, R. Mancini, R. M. M. Nazzari and R. Samperi, "Fate of Natural Estrogen Conjugates in Municipal Sewage Transport and Treatment Facilities," Science of the Total Environment, Vol. 302, No. 1-3, 2003, pp. 199-209. doi:10.1016/S0048-9697(02)00342-X

[16] F. S. Li, R. Desmiarti, A. Yuasa and A. Horio, "Behavior of Natural Estrogens in Semicontinuous Activated Sludge Biodegradation Reactors," Bioresource Technology, Vol. 99, No. 8, 2008, pp. 2964-2971. 
doi:10.1016/j.biortech.2007.06.016

[17] G. G. Ying, R. S. Kookana and P. Dillon, "Sorption and Degradation of Selected Five Endocrine Disrupting Chemicals in Aquifer Material," Water Research, Vol. 37, No. 15, 2003, pp. 3785-3791. doi:10.1016/S0043-1354(03)00261-6

[18] R. Desmiarti, F. S. Li, T. Kawaguchi and C. Yoshimura, "Behavior of Natural Estrogens in Sediment: Column Studies and Model Evaluation," Environmental Engineering Research, Vol. 45, 2008, pp. 535-545.

[19] J. H. Shi, S. Fujisawa, S. Nakai and M. Hosomi, "Biodegradation of Natural and Synthetic Estrogens by Nitrifying Activated Sludge and Ammonia-Oxidizing Bacte- rium Nitrosomonas Europaea," Water Research, Vol. 38, No. 9, 2004, pp. 2323-2330. doi:10.1016/j.watres.2004.02.022

[20] Y. X. Ren, K. Nakano, M. Nomura, N. Chiba and O. Nishimura, "Effects of Bacterial Activity on Estrogen Removal in Nitrifying Activated Sludge," Water Research, Vol. 41, No. 14, 2007, pp. 3089-3096. doi:10.1016/j.watres.2007.04.028

[21] U. Taro and K. Tomoya, "Separate Estimation of Adsorption and Degradation of Pharmaceutical Substances and Estrogens in the Activated Sludge Process," Water Research, Vol. 39, No. 7, 2005, pp. 1289-1300. doi:10.1016/j.watres.2005.01.01 